\title{
Assessing ion-exchange properties and purity of lipophilic electrolytes by potentiometry and spectrophotometry
}

\author{
Debbie S. Silvester, Ewa Grygolowicz-Pawlak, Eric Bakker* \\ Nanochemistry Research Institute, Department of Chemistry, Curtin University of Technology, \\ GPO Box U1987, Perth, 6845, Australia. \\ *E-mail:bakker.eric@gmail.com; Fax:+61(8)92664699; Tel:+61(8)92662743
}

\begin{abstract}
Many ionic salts synthesized using metathesis are often found to contain significant amounts of impurities, despite careful control of the weighing of starting materials. In this work, a potentiometric method is devised to monitor ion-exchange properties (or 'purity') of an organic solvent containing a lipophilic electrolyte. Its permselective behaviour is monitored by treating the solvent as a liquid membrane and contacting it with two aqueous solutions with different electrolyte activities. This electrolyte mismatch results in a drastic potential change when excess lipophilic cation-exchanger is titrated with anion-exchanger, altering the membrane from being cation to anion responsive. Here, the cation-exchanger potassium tetrakis(4-chlorophenyl)borate (KTpClPB) dissolved in nitrobenzene was titrated with tetradodecylammonium chloride (TDDACl), in contact with $\mathrm{Ag} / \mathrm{AgCl}$ electrodes placed in aqueous $1 \mathrm{M}$ and $10^{-2} \mathrm{M} \mathrm{KCl}$, respectively. The predicted potential change of $-214 \mathrm{mV}$ was observed at the equivalence point, forming the inert lipophilic electrolyte ETH 500, in a very small concentration range of added anion-exchanger ( $0.8 \%$ for $\pm 10 \mathrm{mV}$ ), suggesting good precision. The approach was confirmed by monitoring absorbance and fluorescence intensity changes of the chromoionophore Nile Blue. This method may be applied for the synthesis of a range of highly lipophilic salts for which established metathesis protocols are not suitable.
\end{abstract}

\section{Keywords}

ETH 500, potentiometry, ionic liquid purity, inert lipophilic electrolyte purity, Nile Blue, spectrophotometry 


\section{Introduction}

Many ionic salts, including room temperature ionic liquids are often made by synthetic methods such as metathesis [1-3], which rely on the precise weighing of the two starting materials and the assumption that both salts are entirely pure. In many cases, the starting materials can often be impure or contain significant amounts of impurities e.g. dissolved water. As a result, the salts obtained by such methods can themselves be impure $[4,5]$ and often require several follow-up synthetic steps e.g. halide removal by washing with water [6]. Although the purity can be monitored by methods such as cathodic stripping voltammetry [6], salts made in this way are unlikely to be truly halide-free.

For some specialist applications, there is a requirement for a highly pure salt. For example, inert lipophilic salts of high purity are important in electrochemical sensors based on electrochemistry at the interface between two immiscible electrolyte solutions (ITIES) [7], polymeric membrane-based potentiometric [8] and voltammetric sensors [9], where the resulting permselectivity must be carefully controlled.

In this work, we have devised a method to monitor the purity (or ion-exchange properties) of an inert lipophilic salt using potentiometry at the ITIES [7]. The salt chosen is tetradodecylammonium tetrakis(4-chlorophenyl)borate (TDDACITpCIPB or ETH 500), a highly lipophilic salt commonly used in membranes of ion-selective electrodes $[10,11]$. The starting materials are the potassium salt of the anion (KTpClPB) and the chloride salt of the cation (TDDACl). By measuring the membrane potential between two aqueous solutions of different ion activities, in contact with an organic phase containing either excess KTpCIPB (cation-exchanger) and TDDACl (anion-exchanger), it is possible to potentiometrically monitor the ion-exchanger properties of the organic phase, and determine the potential at which the membrane possesses neither anion- nor cationexchanger properties. It is predicted that at this potential, the molar concentrations of the two salts are equal, and a highly pure lipophilic salt can be obtained. We confirm the feasibility of the potentiometric method by monitoring absorbance and fluorescence changes of a chromoionophore, related to a previously reported method [12]. It is 
believed that this work can be applied to a wide range of salts or ionic liquids, provided they are sufficiently lipophilic to remain in the organic phase.

\section{Experimental}

\subsection{Chemicals}

Potassium chloride (Fluka $\geq 99.5 \%$ ), potassium tetrakis(4-chlorophenyl)borate (KTpClPB, Fluka $\geq 98 \%$ ) and tetradodecylammonium chloride (TDDACl, Fluka $\geq 97 \%$ ) were used as received. Nitrobenzene (Sigma-Aldrich 99\%) was washed several times in aqueous $0.1 \mathrm{M} \mathrm{NaOH}$ (APS Finechem $>97 \%$ ) to remove coloured impurities (e.g. nitrophenol) then with water to remove $\mathrm{NaOH}$. $0.1 \mathrm{M}$ aqueous buffer of sodium bicarbonate ( $\mathrm{BDH} \geq 99.7 \%$ ) was adjusted to $\mathrm{pH}=7$ using $1 \mathrm{M} \mathrm{HCl}$. Solutions of Nile Blue A, $\left(10^{-6} \mathrm{M},\left(\mathrm{C}_{20} \mathrm{H}_{20} \mathrm{~N}_{3} \mathrm{O}\right)_{2} \bullet \mathrm{SO}_{4}\right.$ Sigma, dye content $\left.89 \%\right)$ in nitrobenzene were treated with $0.1 \mathrm{M} \mathrm{NaOH}$ to reduce the dye to the non-protonated (neutral) state.

\subsection{Potentiometry}

Potentiometric experiments were conducted in a stirred solution at $22^{\circ} \mathrm{C}$ using a 16 channel mV-meter (Lawson Labs Inc., Malvern, PA) in a fume cupboard. The "reference" electrode was connected to a $\mathrm{Ag} / \mathrm{AgCl}$ wire immersed in $c a .3 \mathrm{~mL} 1 \mathrm{M} \mathrm{KCl}$ (aq) inside a glass pipette. The "measuring" electrode was connected to a similar wire immersed in $3 \mathrm{~mL} 10^{-2} \mathrm{M} \mathrm{KCl}$ in a glass pipette. The tips of the pipettes were modified with Celgard 2500 (polypropylene porous diaphragm/membrane) to prevent leaking/mixing of the phases, and to allow transfer of ions through the phase boundary. Both electrodes were immersed directly into the organic phase of a two-phase system containing $10^{-4} \mathrm{M}$ KTpClPB in nitrobenzene $(50 \mathrm{~mL}$ ) and an aqueous bicarbonate buffer $(\mathrm{pH}=7,10 \mathrm{~mL})$. The cell in shorthand notation is written as: $\mathrm{Ag}(\mathrm{s}) / \mathrm{AgCl}(\mathrm{s}) / 1 \mathrm{M}$ $\mathrm{KCl}(\mathrm{aq}) /$ celgard diaphragm $/ 10^{-4} \mathrm{M}$ KTpClPB $+\mathrm{XmM}$ TDDACl in nitrobenzene(org)/celgard diaphragm/10 ${ }^{-2} \mathrm{M} \mathrm{KCl}(\mathrm{aq}) / \mathrm{AgCl}(\mathrm{s}) / \mathrm{Ag}(\mathrm{s})$.

\subsection{Spectroscopy}

UV/Vis spectra were taken over $\lambda=400-800 \mathrm{~nm}$ with a UV/Vis 916 GBC spectrophotometer, with peak intensities recorded at $\lambda=654 \mathrm{~nm}$ and $\lambda=519 \mathrm{~nm}$ for the 
protonated and non-protonated forms of Nile Blue. Fluorescence measurements were taken at standard right angle configuration on a Jasco FP-6200 spectrofluorimeter, using a 150W xenon lamp. Solutions were excited at $\lambda=636 \mathrm{~nm}$ and spectra taken at $\lambda=500$ $730 \mathrm{~nm}$. Peak intensities were recorded at $\lambda=661 \mathrm{~nm}$ for protonated Nile Blue. A bicarbonate buffer solution (see Section 2.1) was added to the organic phase for the reasons described in Section 4.2.

\section{Theory}

We consider a system with an organic phase in contact with two aqueous phases of different ion activities. According to the phase boundary potential model [13] the potential generated between the phase boundaries (defined as membrane potential) is given by the following form of the Nernst equation:

$$
E=\frac{R T}{z_{\mathrm{I}} F} \ln \frac{a_{\mathrm{I}}\left(a q_{1}\right)}{a_{\mathrm{I}}\left(a q_{2}\right)}
$$

where $E=$ membrane potential, $\mathrm{z}_{\mathrm{I}}=$ charge on the ion $(+1$ or -1$)$ and $a_{\mathrm{I}}=$ activity of the ion I, in the two indicated aqueous phases. $R, T$ and $F$ are the universal gas constant, the absolute temperature and the Faraday constant, respectively.

In the presence of cation-exchanger $\left(R^{-}\right)$in the organic phase, $z_{\mathrm{I}}=+1$, the generated potential is positive. When anion-exchanger $\left(\mathrm{R}^{+}\right)$is added at a concentration in excess of cation-exchanger, the membrane potential switches from cationic response to anionic response, with a potential equal to equation 1 , but with a negative sign, since $z_{\mathrm{I}}=-1$. Figure 1 represents this behaviour schematically, with a sharp transition expected from positive to negative potentials for a truly ideal system. When the molar ratio of the two salts is exactly equal to 1 , a membrane potential of $0 \mathrm{mV}$ is expected. It should therefore be experimentally possible to titrate $\mathrm{R}^{+}$into a solution containing $\mathrm{R}^{-}$in the organic phase, and to stop at the position where the molar ratio of the two lipophilic salts equals 1 to obtain pure $\mathrm{R}^{+} \mathrm{R}^{-}$. The principle was demonstrated here with salts of $\mathrm{TpClPB}^{-}$and $\mathrm{TDDA}^{+}$, since the product, ETH 500 is an important salt used in many ion-selective electrode membranes. 


\section{Results and Discussion}

\subsection{Potentiometry}

The potentiometric response of two Ag/AgCl electrodes measured against each other and separated with an organic phase containing KTpClPB was examined as a function of TDDACl addition to the organic phase. Nitrobenzene was chosen over 1,2dichloroethane (DCE) as the organic solvent, as the potential response was very unstable and erratic in DCE. Additionally, KTpClPB was only sparingly soluble (ca. $\left.10^{-4} \mathrm{M}\right)$ in DCE, but more soluble $\left(>10^{-3} \mathrm{M}\right)$ in nitrobenzene. As a result, nitrobenzene was used as the organic phase solvent for all experiments reported in this work.

For the inner electrolyte of the electrodes, $\mathrm{KCl}$ was employed, since this acts to define the potential at the $\mathrm{Ag} / \mathrm{AgCl}$ wire. Solutions containing other more lipophilic ions compared to chloride (e.g. $\mathrm{KNO}_{3}$ and $\mathrm{KClO}_{4}$ ) were predicted to show broader curves that are less desired. The concentrations of $\mathrm{KCl}$ in the electrodes were chosen to be $1 \mathrm{M}$ and $10^{-2} \mathrm{M}$, sufficiently high to ensure the aqueous phase boundary concentrations remain essentially unchanged in the course of the experiment. According to the theory (section 3), and considering activities of $0.602 \mathrm{M}$ and $0.901 \times 10^{-2} \mathrm{M}$, respectively, a membrane potential of $+107 \mathrm{mV}$ is predicted for the cation-exchanger response, and $-107 \mathrm{mV}$ for the anionexchanger response.

Figure 2 shows the potential monitored for the potentiometric cell upon titration of a $10^{-}$ ${ }^{4} \mathrm{M}$ KTpClPB nitrobenzene solution with $10^{-2} \mathrm{M}$ TDDACl. The experimental emf was converted to membrane potential, defined as the potential difference between the $1 \mathrm{M}$ $\mathrm{KCl} / \mathrm{NB}$ and $\mathrm{NB} / 10^{-2} \mathrm{M} \mathrm{KCl}$ phase boundaries. As predicted by the theory, the membrane potential was initially $107( \pm 3) \mathrm{mV}$ (only KTpClPB present) and dropped to $-107( \pm 4) \mathrm{mV}$ with excess TDDACl. The transition is relatively sharp, but deviates slightly from ideal behaviour at the endpoint, as is common in many titration experiments. The position of the endpoint lies within a very small concentration range for $R^{+}(0.8 \%$ for $\pm 10 \mathrm{mV})$, sufficiently precise for practical use. For the two salts employed in this study, the value for the endpoint corresponds to $c a .1 .2 \times 10^{-4} \mathrm{M}$ of added TDDACl, which is an excess of $20( \pm 5) w t \%$ (over 5 experiments) compared to the expected quantity required to neutralise 
KTpCIPB. The lack of consistency is most likely due to impurities present in the TDDACl salt, as observed previously $[14,15]$, although impurities in KTpClPB are also possible. Partial solubility of TDDACl in the aqueous buffer can be ruled out, since repeated washing of the titrant with buffer solution did not alter the position of the endpoint. The discrepancy must be considered in synthetic experiments containing such salts (e.g. metathesis), since the molar mismatch of salts can affect the purity of the final inert lipophilic salts. This clearly shows the importance of reliable monitoring of the molar ratios of the inert salts during synthesis and is the motivation for the potentiometric method described here.

\subsection{Spectrophotometry}

To confirm the accuracy of the proposed potentiometric method, the composition changes were monitored spectrophotometrically using a hydrogen ion-selective chromoionophore that changes absorbance and fluorescence depending on the degree of protonation [10]. The dye is placed in the organic phase, and in the presence of cation-exchanger, cations undergo an exchange with hydrogen ions in the adjacent water phase and the dye becomes protonated. When excess anion-exchanger is titrated in, the indicator dye (Ind) becomes deprotonated and a colour change is observed:

$\operatorname{IndH}_{(\text {org) }}^{+}+\mathrm{R}_{(\text {org) }}^{-}+\mathrm{R}^{+} \mathrm{Cl}_{(\text {org })}^{-} \rightarrow \mathrm{R}^{+} \mathrm{R}_{(\text {org) }}^{-}+\mathrm{HCl}_{(\mathrm{aq})}+\operatorname{Ind}_{(\text {org })}$

The chromoionophore Nile Blue was chosen here as an indicator for the lipophilic cationexchanger. In the presence of KTpClPB the dye is protonated (blue colour), and dye becomes neutral (red colour) with excess TDDACl.

The ion exchange also causes a change in $\mathrm{pH}$ of the aqueous phase, which may be significant considering its small volume. As a result, nitrobenzene was conditioned with $\mathrm{pH}$ buffer $(\mathrm{pH}=7)$ of larger volume. An emulsion was then formed, which resulted in much difficulty collecting clean UV/Vis spectra. To overcome this, $\mathrm{KCl}$ was added to the system, which partially helped to separate the two phases so that spectra could be recorded, but had no effect on the emf response of the electrodes. The spectra were 
corrected for sloping baselines (due to non-transparent solutions) so that peak intensities could be directly compared. Peak absorbance for protonated Nile Blue occurred at $\lambda=654$ $\mathrm{nm}$, and unprotonated at $\lambda=519 \mathrm{~nm}$. As shown in Figure 3 (squares), absorbance peak intensity decreased systematically for the protonated form of Nile Blue, suggesting the expected solution composition changes according to equation 2. A visual colour change from blue to red (green to orange in yellow coloured nitrobenzene) was observed at the position marked with an arrow on Figure 3 corresponding exactly to the half way point of maximum absorbance intensity. This is also the point at which the membrane potential passed through $0 \mathrm{mV}$.

A second complimentary fluorescence method was also employed. The intensity of the peak decreased as TDDACl was added. Figure 3 (triangles) shows fluorescence intensity vs. added TDDACl concentration, compared to absorbance (squares). Fluorescence intensity decreased in a similar pattern to absorbance, and the visual colour change was also observed at the half-way point of fluorescence intensity. Fluorescence was found to be more sensitive and more reliable than absorbance due to the presence of nontransparent solutions, as baseline correction for fluorescence spectra was not required. Both methods have been shown to compliment the potentiometric method suggested in section 4.1.

\section{Conclusions}

The potentiometric method proposed in this work has been shown to conform well to theoretical predictions based on the phase boundary potential model. The potential jump observed from excess $\left[R^{-}\right]$to excess $\left[R^{+}\right]$in the organic phase was predicted by the Nernst equation. The endpoint of the titration (where $\left[R^{-}\right]=\left[R^{+}\right]$) occurs over a very small concentration range for $\left[\mathrm{R}^{+}\right]$, suggesting that the method is very precise. The potentiometric method is expected to be more precise than absorbance, since emulsion solutions can make absorbance measurements difficult. Fluorescence spectroscopy was more reliable than absorbance since no baseline correction of spectra was required. The salts chosen in this work will form the lipophilic salt ETH 500, but this method can also 
be applied to other types of ionic solids and liquids so long as they are sufficiently lipophilic and modestly soluble in the organic phase.

\section{Acknowledgements}

The authors thank the Australian Research Council (DP0987851), Curtin University for a Curtin Research Fellowship (D.S.S.), and Dr. Gareth Nealon (Curtin) for useful discussions. 


\section{References:}

[1] P. Bonhôte, A.-P. Dias, M. Armand, N. Papageorgiou, K. Kalyanasundaram, M. Grätzel, Inorg. Chem. 35 (1996) 1168-1178.

[2] J. Langmaier, Z. Samec, Electrochem. Commun. 9 (2007) 2633-2638.

[3] H.J. Lee, H.H. Girault, Anal. Chem. 70 (1998) 4280-4285.

[4] K.R. Seddon, A. Start, M.-J. Torres, Pure Appl. Chem. 72 (2000) 2275-2287.

[5] D.S. Silvester, R.G. Compton, Z. Phys. Chem. 220 (2006) 1247-1274.

[6] C. Villagrán, C.E. Banks, C. Hardacre, R.G. Compton, Anal. Chem. 76 (2004) 1998-2003.

[7] Z. Samec, E. Samcová, H.H. Girault, Talanta 63 (2004) 21-32.

[8] M. Nägele, Y. Mi, E. Bakker, E. Pretsch, Anal. Chem. 70 (1998) 1686-1691.

[9] S. Jadhav, E. Bakker, Anal. Chem. 73 (2001) 80-90.

[10] E. Bakker, P. Bühlmann, E. Pretsch, Chem. Rev. 97 (1997) 3083-3132.

[11] A. Legin, S. Makarychev-Mikhailov, J. Mortensen, Y. Vlasov, Electrochim. Acta 49 (2004) 5203-5207.

[12] R.E. Gyurcsányi, E. Lindner, Anal. Chem. 74 (2002) 4060-4068.

[13] E. Bakker, P. Bühlmann, E. Pretsch, Talanta 63 (2004) 3-20.

[14] E. Bakker, PhD Thesis, Eidgenössische Technische Hochschule, Zürich 1993.

[15] E. Bakker, P. Bühlmann, E. Pretsch, Electroanalysis 11 (1999) 915-933. 
Figures:

Figure 1

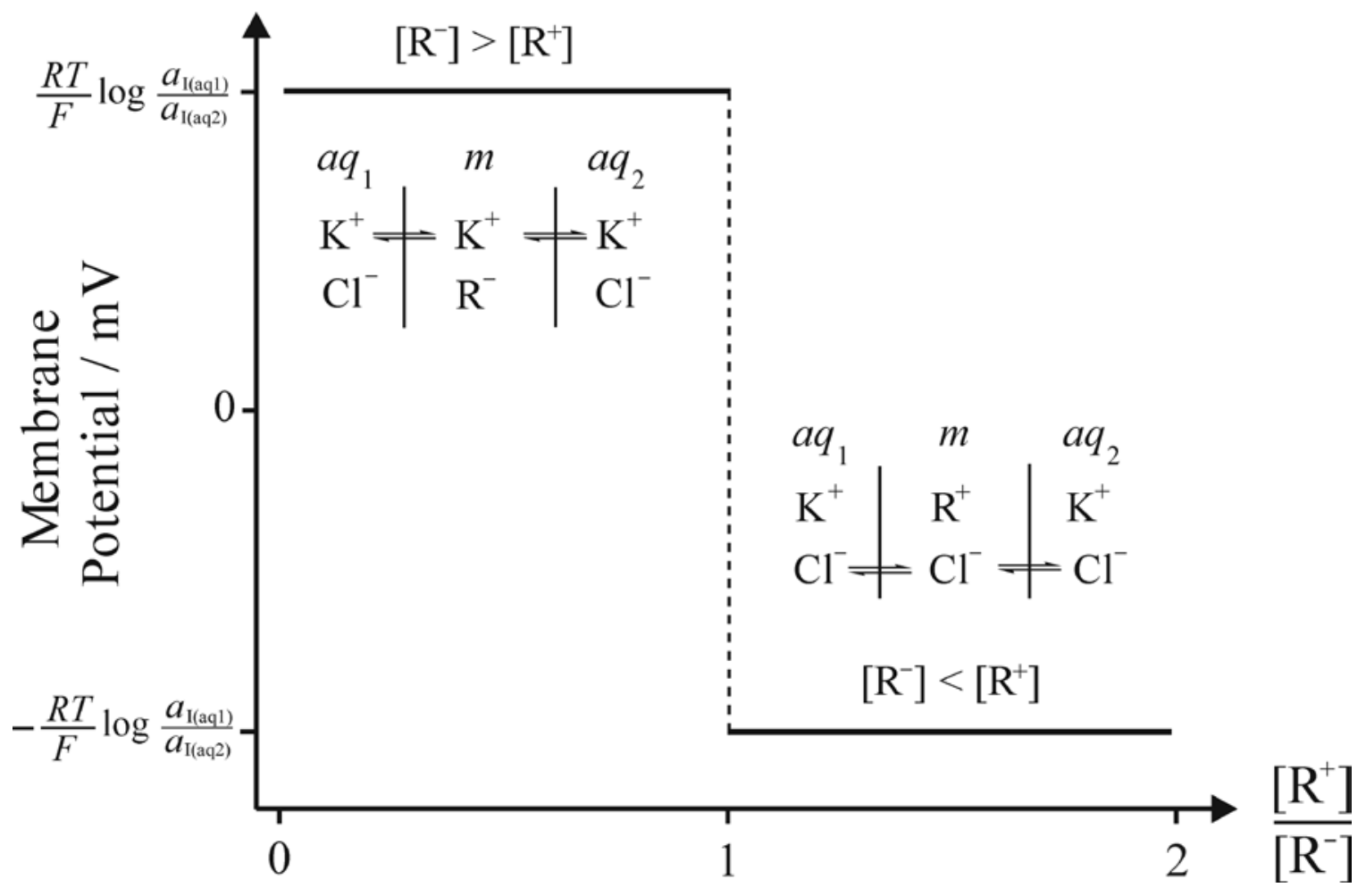


Figure 2.

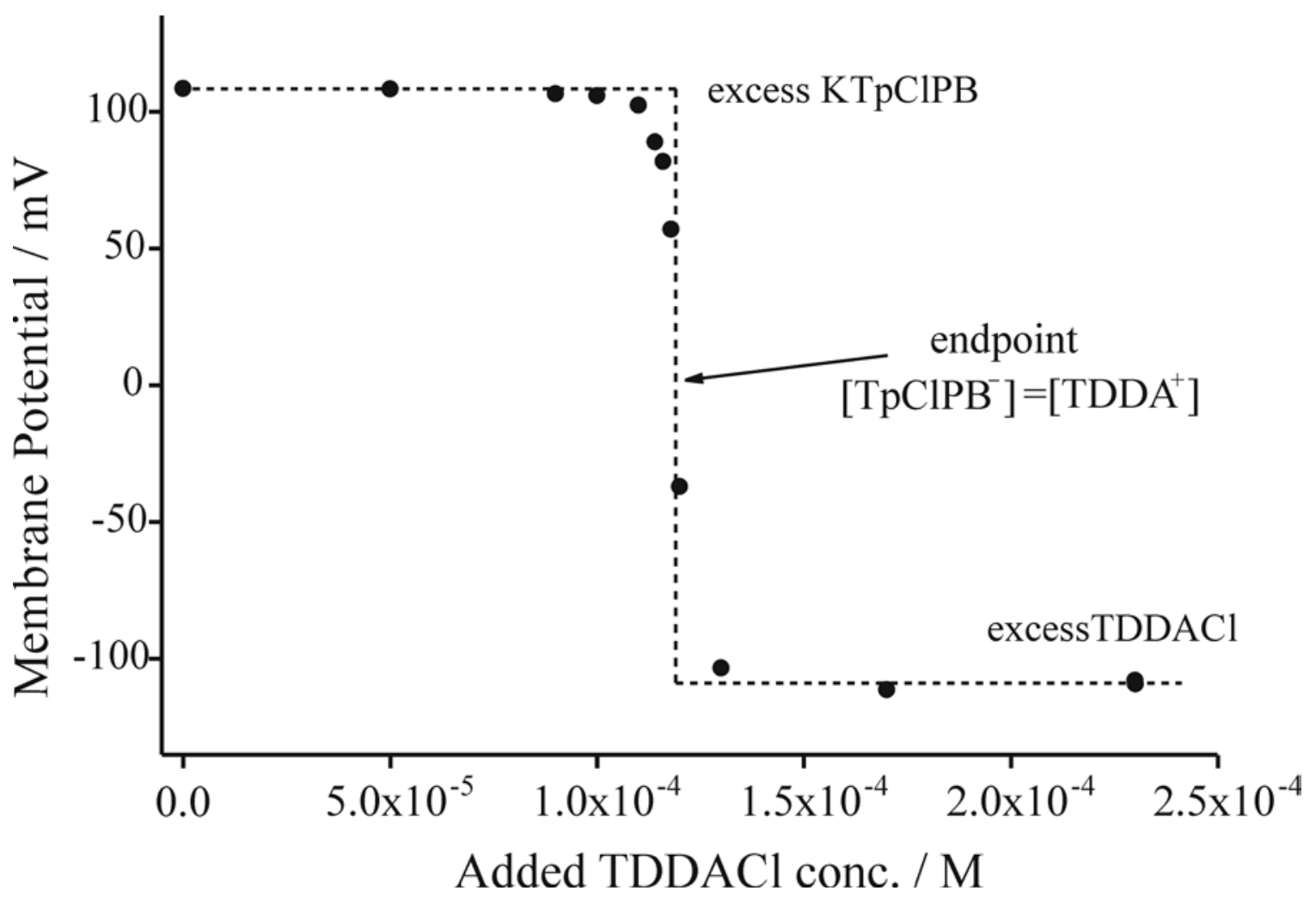


Figure 3.

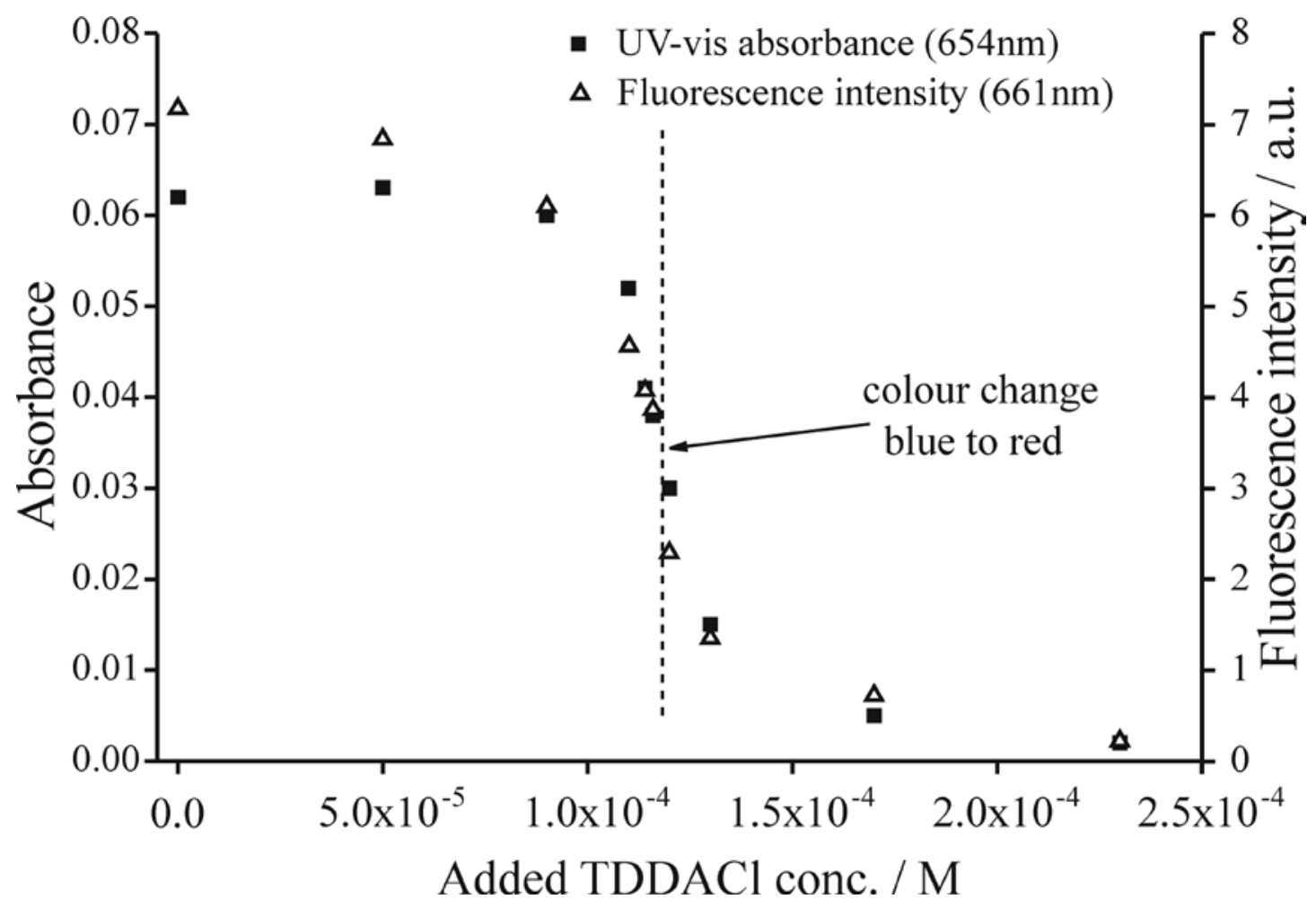


Figure 1. Predicted theoretical response of the electrochemical cell employed in this study. In the presence of excess cation-exchanger [ $\left.\mathrm{R}^{-}\right]$, a positive potential is expected, with the magnitude given by the Nernst equation. In the presence of excess anionexchanger [R+], a negative potential is expected, given by the Nernst equation.

Figure 2. Titration of $10^{-4} \mathrm{M} \mathrm{KTpClPB}$ with TDDACl in nitrobenzene, buffered with a $0.1 \mathrm{M} \mathrm{NaHCO}_{3}$ buffer at $\mathrm{pH}=7$. Aqueous inner electrolyte solutions were $1 \mathrm{M}$ and $10^{-2} \mathrm{M}$ $\mathrm{KCl}$, respectively. Circles: experimental data points. Dotted line: ideal theoretical response as shown in Figure 1.

Figure 3. Squares: UV/Vis intensity of absorbance peak at $\lambda=654 \mathrm{~nm}$ (protonated chromoionophore) as a function of increasing concentration of anion-exchanger (TDDACl). Triangles: Fluorescence emission intensity $(\lambda=661 \mathrm{~nm})$ as a function of increasing concentration of TDDACl. Vertical dotted line in the same position as Figure 2. 